Braga, S.S.; Vieira, L.M. Análise da viabilidade turística e cultural do carnaval de Belo Horizonte (MG). Revista Brasileira de Ecoturismo, São Paulo, v.6, n.5, nov-2013/jan-2014, pp.910925.

\title{
Análise da viabilidade turística e cultural do carnaval de Belo Horizonte (MG)
}

\author{
Analysis of touristic and cultural feasibility of the Belo Horizonte's \\ (MG, Brazil) carnival
}

\section{Solano de Souza Braga, Leandro Martins Vieira}

\begin{abstract}
RESUMO
O carnaval é uma das festas populares mais importantes do Brasil. Em muitas metrópoles do país o evento toma proporções gigantescas, desta maneira, se constitui como um grande produto turístico. Em Belo Horizonte, ao contrário, as comemorações "momescas" não possui a participação que se verifica em outras cidades do mesmo porte. Apesar do esforço da prefeitura e entidades voltadas para a questão turística em proporcionar ajuda financeira e, de certa maneira, infraestrutura para a realização do carnaval em Belo Horizonte, ele evolui de maneira muito tímida, contrariando as expectativas de seus idealizadores. Este trabalho visa a análise de fatos e dados sobre o carnaval e outros eventos na capital de Minas Gerais, a viabilidade dos investimentos públicos para a promoção deles e quais caminhos deverão ser seguidos para a promoção turística na cidade nesta época do ano. Esta pesquisa tem por objetivo analisar a realização dos investimentos públicos no carnaval em Belo Horizonte e sua importância cultural, turística e para população local. Desta forma, realizou-se um estudo de caso que abrange questões sobre a história do carnaval e turismo cultural. Por fim, chegou-se a conclusão que mesmo com a pouca participação popular, as festas são de grande importância como opção de lazer para as camadas menos favorecidas economicamente que habitam a cidade.
\end{abstract}

PALAVRAS-CHAVE: Carnaval; Cultura; Eventos; Belo Horizonte.

\begin{abstract}
Carnival is the important popular festival in Brazil. In many metropolis of the country the event takes gigantic proportions, thus, constitutes itself as a major tourism product. In Belo Horizonte (MG), on the contrary, the "momescas" celebrations don't have the participation seen in other cities of similar size. Despite the efforts of city government and entities focused on the issue of tourism to provide financial assistance and infrastructure in a way to perform carnival in Belo Horizonte, it has evolved very shy, contrary to the expectations of its creators. This work aims at analyzing facts and figures about the carnival and other events in the capital of Minas Gerais, the viability of public investments to promote them and what paths should be followed to promote tourism in the city, this time of year. The present paper aims to analyze the performance of public investment at the carnival in Belo Horizonte and its cultural, tourist and local population. In this matter it was done a case study that includes questions about the history of carnival cultural tourism. With that came to the conclusion that even with little popular participation, the parties are of great importance as a leisure option for the economically disadvantaged sections inhabiting the city.
\end{abstract}

KEYWORDS: Carnival; Culture; Events; Belo Horizonte.

Página 910 Revista Brasileira de Ecoturismo, São Paulo, v.6, n.5, nov 2013-jan 2014, pp.910-925.

Sociedade Brasileira de Ecoturismo. Rua Dona Ana, 138, Vila Mariana, São Paulo, SP - Brasil. E-mail: rbecotur@sbecotur.org.br; Tel. (55-II) 99196-7685 


\section{Introdução}

O carnaval é notadamente a maior, mais importante e significativa festa popular brasileira. Outros países também o celebram, porém nenhum deles atinge as proporções que conhecemos. Difere, portanto, não só pela participação popular, como também na riqueza, na complexidade, na criatividade e na originalidade dos foliões.

Além disso, o carnaval brasileiro, em diversas cidades, é um dos maiores atrativos turísticos, tanto internacional quando doméstico. De acordo com dados do Instituto Brasileiro de Turismo (EMBRATUR) citados no jornal Gazeta Mercantil na edição de 30 de janeiro de 2005, aproximadamente 200 mil turistas estrangeiros desembarcaram no país no ano de 2004 durante as festas momescas. E levando-se em conta um gasto médio de 90 dólares por dia, os mesmos terão deixado no Brasil aproximadamente US\$ 120 milhões.

Em Belo Horizonte (MG) verifica-se o esvaziamento da cidade no carnaval e, de acordo com o mesmo jornal citado acima no ano de 2004, aproximadamente 1.200 ônibus deixaram a capital mineira na quinta e na sexta-feira que antecederam ao carnaval. No período, a Polícia Rodoviária Federal contabilizou a saída de 300 mil automóveis. Assim, segundo a reportagem, não é exagero afirmar que Belo Horizonte perde pelo menos 500 mil habitantes no período carnavalesco. A prefeitura no intuito de, pelo menos manter parte da população na cidade, ou simplesmente oferecer uma opção para a população impossibilitada de viajar têm investido no carnaval. Mesmo com investimentos na organização de bailes populares, desfiles de escolas de samba, corso carnavalesco entre outros a participação popular é estatisticamente pequena.

Grande parte dos contribuintes contestam as tentativas da Empresa Municipal de Turismo de Belo Horizonte (BELOTUR), considerando-as desnecessárias e excessivamente dispendiosas, tendo em vista o pouco, ou até mesmo nenhum retorno financeiro oferecido à cidade. Alguns chegam a dizer que Belo Horizonte deveria abdicar totalmente ao carnaval, investindo na atração de turistas que não gostam desses festejos. Afirmam ainda, que a cidade poderia usar a seu favor esta imagem de tranquilidade criando eventos e opções de lazer para a população voltada para este contexto.

Outro fator que serve de argumentos para os que defendem o fim do carnaval em Belo Horizonte, são as pesquisas de opinião que tratam da preferência do brasileiro quanto aos festejos do rei Momo. A primeira pesquisa foi realizada pelo Instituto Sensus, por encomenda da CNT (Confederação Nacional do Transporte), em fevereiro de 2004. Em nível nacional verificou-se que $57 \%$ da população brasileira afirma não gostar de carnaval. Já em fevereiro de 2006 o Instituto Nexus realizou uma pesquisa contendo uma questão semelhante, só que dessa vez somente em Belo Horizonte, e o resultado foi praticamente o mesmo, pois $57 \%$ dos belorizontinos afirmaram não gostar de carnaval.

Por outro lado, existem várias pessoas nas diversas regiões da cidade apaixonadas pelo carnaval, que comandam escolas de samba com pouquíssimos recursos, muita criatividade e dedicação, simplesmente com um propósito: não deixar o carnaval "morrer" em Belo Horizonte. Segundo os defensores o carnaval é uma festa de cunho 
popular e não um produto turístico e como tal, pode se tornar uma forma de atração de turistas, mas essa não é sua finalidade principal, o que vai de encontro com Araújo (1991) que analisa a dicotomia entre os festeiros como manifestações da expressão cultural verdadeira do povo e também mercadoria vendida pelos meios de comunicação em massa envoltos de "verniz cultural".

Mesmo com grandes esforços e investimentos da Prefeitura de Belo Horizonte e da BELOTUR o carnaval da capital de Minas Gerais não se desenvolve como grande atrativo para moradores e turistas. Enquanto isso verifica-se uma festa que ocorre em benefício de um pequeno grupo, sem identidade cultural definida e optando simplesmente pela cópia de modelos que são sucesso em outras cidades, principalmente no Rio de Janeiro. Desta forma, o objetivo deste trabalho é fazer um estudo de caso sobre a dinâmica do carnaval em Belo Horizonte e sua importância para a cidade do ponto de vista cultural e de atratividade turística, além de verificar a eficiência dos gastos públicos na realização da festa. Como objetivos específicos destacam-se: a) analisar os investimentos públicos no carnaval de Belo Horizonte; b) identificar os atores responsáveis pela organização dos festejos momescos na cidade e como se organizam; c) viabilidade de investimentos alternativos para atratividade turística no período de carnaval para a cidade.

\section{Procedimentos metodológicos}

A metodologia deste trabalho pode ser classificada como exploratória, por ter como objetivo proporcionar maior familiaridade com o problema, com vistas a torná-lo mais explícito ou a construir hipóteses. Pode-se dizer que esta pesquisa tem como objetivo principal "o aprimoramento de ideias ou a descoberta de intuições" (GIL, 1991, p.46). Já na classificação segundo os procedimentos, este trabalho pode ser definido como ex-post-facto que, segundo Gil (1991), é empregado quando um experimento é realizado utilizando situações e dados, ocorridos naturalmente em períodos anteriores, tendo o pesquisador a possibilidade de testar hipóteses, mas não a capacidade de controle ou manipulação das variáveis. A presente investigação utiliza de metodologia qualitativa através de estudo de caso, voltado para a análise imparcial e sem ideias preconcebidas sobre a viabilidade dos investimentos públicos no carnaval belorizontino, conforme afirma Yin, 2005: Todas as condições precedentes serão invalidadas se o pesquisador procurar utilizar o estudo de caso apenas para comprovar sua teoria preconcebida" (Yin, 2005). Devem-se analisar várias perspectivas, e só assim, tirar conclusões.

Atualmente o estudo de caso é adotado na investigação de fenômenos das mais diversas áreas do conhecimento, permitindo assim, o amplo detalhamento dos objetivos propostos.

(...) um conjunto de dados que descrevem uma fase ou a totalidade do processo social de uma unidade, em que suas várias relações internas e nas suas fixações culturais, quer seja essa unidade uma pessoa, uma família um profissional, uma instituição social, uma comunidade ou uma nação (Yong, 1960 apud Gil, 1987, p.59). 
Também podemos afirmar que a metodologia de estudo de caso busca investigar um fenômeno contemporâneo dentro de seu contexto da vida real, especialmente quando os limites entre o fenômeno e o contexto não estão claramente definidos. Experimentos, levantamentos, pesquisas históricas e análise de informações em arquivos (como em estudos de economia), são alguns exemplos de maneiras de se realizar a pesquisa. Segundo YIN (1984), cada método possui suas vantagens e desvantagens, e a escolha de cada um deles leva em consideração três fatores:
a) Tipo de questão a ser pesquisada;
b) Controle do pesquisador sobre eventos pesquisados;
c) Fenômeno histórico versos fenômeno contemporâneo.

A Cosmos Corporation, empresa de tecnologia de pesquisa e administração especializada em problemas de política social, elaborou um quadro que ilustra as estratégias de pesquisas e quando utilizá-las.

Quadro 1: Situações Relevantes para diferentes estratégias de pesquisa.

Table 1: Relevant situations for different research strategies.

\begin{tabular}{|l|l|c|c|}
\hline \multicolumn{1}{|c|}{ Estratégia } & \multicolumn{1}{|c|}{$\begin{array}{c}\text { Forma da questão } \\
\text { de pesquisa }\end{array}$} & $\begin{array}{c}\text { Exige controle sobre } \\
\text { eventos comporta- } \\
\text { mentais? }\end{array}$ & $\begin{array}{c}\text { Focaliza acontecimen- } \\
\text { tos contemporâneos? }\end{array}$ \\
\hline Experimento & como, por que & $\operatorname{sim}$ & $\operatorname{sim}$ \\
\hline Levantamento & $\begin{array}{l}\text { quem, o que, onde, } \\
\text { quantos, quanto }\end{array}$ & não & sim/não \\
\hline Análise de arquivos & $\begin{array}{l}\text { quem, o que, onde, } \\
\text { quantos, quanto }\end{array}$ & não & não \\
\hline Pesquisa histórica & como, por que & não & sim \\
\hline Estudo de caso & como, por que & não & \\
\hline
\end{tabular}

Fonte: COSMOS Corporation. Source: COSMOS Corporation.

A associação do tema com as duas últimas colunas do quadro. 1 foi de fácil assimilação, uma vez que o pesquisador não possui controle sobre os eventos a serem analisados e $o$ assunto trata-se de um acontecimento contemporâneo. Por meio desse estudo tentar-se-á compreender a dinâmica do carnaval em Belo Horizonte, bem como o interesse da população, turistas e eficácia do uso do investimento público nos festejos. 


\section{Carnaval}

Existem várias hipóteses sobre a origem do termo carnaval. A mais aceita diz que o termo originou-se do latim carnem levare, ou seja, abstenção da carne; isso porque durante a quaresma os cristãos não comiam carne. Por meio da evolução dos idiomas o termo ganhou a denominação de carnevale, ou adeus carne, também como afirmação desse período de abstinência.

Entretanto, independente de qual seja a sua verdadeira etimologia, a palavra carnaval designa, desde a antiguidade, um tipo de festa de cunho pagão caracterizada por comportamentos licenciosos e celebrada entre o fim do ano e o início da primavera, tendo, na era cristã, sido delimitada ao período imediatamente anterior à quaresma (ARAÚJO, 1991).

O carnaval reveste-se de características próprias, segundo o lugar que ocorre. Distingue-se, entre si, os carnavais de Nice, Veneza, Roma, Florença, Nova Orleans e de várias cidades do Brasil como Rio de Janeiro, Salvador e Olinda.

Inclusive no Brasil, o carnaval tomou-se, com certeza, a maior e mais significativa festa popular, conforme afirma Araújo, 1991: "Em nenhuma parte do mundo a festa popular atingiu conjuntamente tamanhas proporções em número de participantes, riqueza, complexidade, extensão, intensidade e originalidade de suas manifestações" (ARAÚJO, 1991 p.6).

Em geral, nas cidades brasileiras, existem três tipos de eventos carnavalescos distintos (Ibidem, p.33):

- Carnaval organizado: composto principalmente por desfiles oficiais ou patrocinados pelo poder público ou órgão de imprensa e comunicação, que congregam escolas de samba, blocos e outros tipos de sociedades carnavalescas;

- Carnaval espontâneo: são as folias de rua, próprias do carnaval popular, composta de foliões isolados e agregados espontâneos ou pouco estruturados e aberto à participação de qualquer pessoa;

- Carnaval de salão: bailes e festas fechadas, realizados principalmente pelos clubes de acesso restrito a sócios, convidados e pagantes.

O primeiro e o terceiro tipo caracterizam-se, principalmente, pela organização e pelo caráter excludente, sendo que um é composto por membros, alguma organização ou comunidade e/ou outro. Destaca-se também a questão financeira no caso da compra de convites. Já o carnaval espontâneo apresenta um lado mais democrático e diverso do carnaval. 


\section{Carnaval no Brasil}

A primeira manifestação que chegou ao Brasil trazida pelos portugueses foi o "entrudo" que se origina no termo "introito", ou entrada na Quaresma. "Festa portuguesa violenta que nada tinha de erótica: atacavam-se as pessoas com jatos 'água, farinha, lama, ovos e legumes podres..." (ARAÚJO, 1991 p.16). Mas, somente ao longo dos anos quando começa a haver uma integração dos elementos do entrudo com características folclóricas e culturais do Brasil que a festa começa a ganhar popularidade entre o povo. Já na época do império, segundo Araújo (1991) começa a surgir os primeiros grupos de Zé-Pereira, e mesmo o entrudo passou por modificações quando os antigos materiais foram substituídos por balões com água perfumados.

Em 1840, no Hotel D'Itália no Rio de Janeiro ocorreu o primeiro baile carnavalesco seguindo a tradição europeia. Logo após esse evento outras cidades importantes como São Paulo, Salvador e Recife seguiram o exemplo. Já no inicio do século $X X$, uma onda de criatividade musical assolou o carnaval brasileiro. Surgiu o samba e as marchinhas no Rio de Janeiro, o frevo e o maracatu em Recife. São Paulo, por sua vez, criou o corso de automóveis em substituição aos desfiles de carruagens em 1911. É importante ressaltar que este momento de grande criação e modificação das estruturas do carnaval coincide com os primeiros anos após a libertação dos escravos. Consequentemente, houve uma grande fusão entre os ritmos até então populares do carnaval com as tradições musicais africanas trazidas pelos ex-escravos. No ano de 1928 surge a primeira escola de samba chamada "Deixa Falar," posteriormente a "Escola de Samba Estação Primeira de Mangueira, que em 1932, ganhou o 1ํ lugar no primeiro concurso de escolas de samba” (ARAÚJO, 1991, p.19).

Outro marco importante no carnaval ocorreu em 1950, em Salvador, quando os músicos Dodô e Osmar montaram uma aparelhagem de som sobre um caminhão, surgindo assim o famoso "trio elétrico" que anima o carnaval de Salvador e várias cidades ao país.

\section{Contextualização histórica do carnaval de Belo Horizonte}

A História do carnaval de Belo Horizonte remonta à criação da nova capital. Com apenas 67 dias da instalação, sob a denominação de Cidade de Minas, começou o carnaval do ano de 1898 nos dias 20, 21 e 22 de fevereiro. Segundo Barreto (1929), nesses primeiros dias de vida da Capital um bom número de mascarados saiu às ruas, mesmo timidamente, para brincar o Carnaval. Paralelamente, vários bailes particulares aconteceram em residências promovidos pela juventude. Alguns boêmios alugaram um grande salão na Avenida Paraopeba, entre as Ruas da Bahia e Espírito Santo, e realizaram bailes de máscaras durante as três noites ao som polcas, valsas, schottisk, quadrilhas e maxixes até ao amanhecer.

Já no ano de 1904 houve a fundação do Clube Matakins e, através dele, os primeiros desfiles com carros ornamentados e fantasiados denominados $\mathrm{O}$ Corso. Esses desciam a Avenida Afonso Pena, a partir da Avenida Carandaí, lentamente até a 
Praça Sete. "Os blocos fantasiados nos carros trocavam confetes, serpentinas e lança -perfume, um com os outros e com as pessoas que estavam nas calçadas". (VELOSO, 1995).

Paralelamente, existiam os desfiles de fantasia e bailes infantis de clubes como o Automóvel Clube, Minas Tênis e outros. Também, nessa época, os bares da rua da Bahia, Trianon e Bar do Ponto forneciam uma boa infraestrutura para o carnaval nessa mesma rua. Outro bloco de destaque foram "as gatinhas", que era composto por moças que vestiam calças compridas, luvas, capuz no rosto com orelhinhas na cabeça, abertura na altura dos olhos e com bigodes de gatos pintados.

A partir da década de 1970 houve uma tendência não só em Belo Horizonte, mas em quase todo o Brasil de tentar copiar o desfile das escolas de samba do Rio de Janeiro. O poder público municipal investiu grandes quantias com esse propósito e alguns blocos se tornaram escolas de samba e outras foram criadas. Na década de 1980, com a criação das administrações regionais, passaram-se a realizar bailes populares em cada uma das nove regionais, os chamados "bailes do povão", que aconteciam no centro da cidade, mais precisamente nas Praças da Estação e Rodoviária.

Em 1990 encerraram-se os desfiles das escolas de samba. Os custos de sua realização tornaram-se cada vez maiores, tanto na organização, quanto no patrocínio das escolas, feito pela prefeitura. A partir do ano de 2004, numa tentativa de resgate, as escolas de samba e a Belotur organizaram o desfile na Via 240 no bairro Aarão Reis. Além das escolas, desfilara nesse local os blocos carnavalescos e caricatos. No ano de 2006, além da organização do desfile, a prefeitura patrocinou a gravação de um CD com os sambas enredos, que deveria ser usado como fonte de atração de recursos para as escolas, mas o objetivo não foi alcançado devido ao número pequeno de cópias vendidas.

\section{Carnaval, uma manifestação cultural}

O carnaval é uma manifestação de cultura popular das mais importantes do Brasil, se não, a mais importante. Não é sem motivo que dizem: que o ano só começa de verdade quando termina o carnaval. Segundo Coelho (2003), as festas são um importante instrumento para se compreender a cultura popular. "O carnaval é a oportunidade de interagir com o mítico, o religioso e a realidade, que compõe o imaginário popular" (COELHO, 2003).

Portanto, o carnaval é uma festa popular, por isso fundamental dentro das culturas nas quais estão inseridas. Para Crowhust e Lennard (apud Meléndes 2002) as festividades e as celebrações são essenciais para a vida humana. Elas contribuem a dar vitalidade à vida cotidiana e pelo caráter social que possuem são indispensáveis para a saúde da sociedade. Além disso, Meléndes (2002), afirma que as festividades são fonte de integração social, uma vez que, por meio delas, os mais jovens se colocam em contato com costumes do passado e podem compreender-se como parte integrante de um tecido social estabelecido. 
Sugere ainda Coelho (2003), "o carnaval é a festa que mais reúne diferenças em todo o território brasileiro, principalmente porque é celebrado por todas as camadas da população". Até aqueles que não participam diretamente da festa, aproveitam o período para viajar ou descansar.

O carnaval brasileiro como instrumento cultural, serve também como ferramenta de "folkcomunicação" que pode ser definida como os aspectos de comunicação das manifestações culturais, "seria a ciência da comunicação através dos sistemas do folclore" (COSTA; ANDRADE, 2003). No carnaval podemos realmente observar essa comunicação das camadas populares, através dos desfiles das escolas de sambas, dos blocos e até mesmo nos bailes fechados. Por meio disso, Araujo (1991) levanta a polêmica se o carnaval hoje é um instrumento de folkcomunicação ou mercadoria vendida pelos meios de comunicação em massa, ou até mesmo as duas coisas.

Com isso, algumas manifestações regionais típicas de determinados carnavais vêm perdendo força e tendem a desaparecer, sufocadas pelos modelos cariocas e baianos, dependendo da cidade. Isso ocorre, principalmente, pela falta de apoio do poder público e até mesmo o desinteresse das populações locais. Sendo assim, aumenta o caráter turístico da festa. Nas cidades com o carnaval consolidado o poder público, juntamente com a iniciativa privada, tenta atrair a todo custo os foliões. Desta forma, observa-se a dinâmica cultural das festas carnavalescas e a maneira como elas se interagem com as necessidades e mudanças de comportamento do povo brasileiro ao longo dos anos.

\section{Turismo cultural}

A relação entre a cultura e o turismo é notada quando há apropriação das manifestações culturais de uma localidade pelo turismo. O Patrimônio Cultural de um povo pode tornar-se um grande fator de atratividade turística. De acordo com Beni (2002) o turismo como um sistema aberto, que se move pela oferta variada em determinados destinos, as manifestações culturais podem formar parte de um produto, desde que seja conectada de forma direta ou complementaria os serviços turísticos.

O turismo cultural contempla todos os aspectos através dos quais as pessoas aprendem sobre as formas de vida e pensamento umas das outras. Assim, o turismo é um importante meio para promover relações culturais e cooperação intercultural. Segundo Goeldner, Ritchie e Mcintosh (2002), os elementos sociais e culturais de atratividade turística são: trabalho, vestuário, arquitetura, artesanato, história, idioma, crenças, educação, tradições, atividades de lazer, arte e gastronomia. Praticamente todos os aspectos - com exceção à gastronomia - estão diretamente ligados às tradições carnavalescas, o que torna o produto carnaval, bem completo do ponto de vista do turismo cultural.

De acordo com Batista (2005), o turismo cultural tem como função estimular os fatores culturais dentro de uma sociedade e também é um meio de atrair recursos e incrementar o desenvolvimento econômico da região. Além disso, "a preservação da 
autenticidade da manifestação folclórica é a forma que pode ser encontrada pelas comunidades para resistir às tentativas de homogeneização cultural promovidas pelo processo de globalização" (DIAS; AGUIAR, 2002 p.142).

Segundo Prats (apud RIBEIRO, 1997), coloca as três formas em que o patrimônio (tangível ou intangível) pode ser apresentado como recurso turístico:

- O patrimônio pode se constituir em um produto turístico por ser capaz de integrar junto à oferta hoteleira, um motivo de compra autônoma.

- O patrimônio pode ser apresentado como "associado" a um produto turístico integrado (pacote de viagem), sendo parte integrante de um produto.

- O patrimônio pode se constituir em um valor agregado para destinos turísticos que não possuem atrativo principal ou o motivo de compra básica.

Assim, como o patrimônio complementa o local, cidade ou comunidades onde ocorrem as festas, contribui para agregação de valor cultural e também como elemento de permanência dos turistas. Já no caso das festas, principalmente as que duram vários dias, podem se constituir em uma grande oportunidade de integração entre a comunidade e o turista (MELÉNDES, 2002).

Por outro lado, há uma tendência de massificação e uniformização das formas de comportamentos das festividades. Isso é provocado pelas necessidades da sociedade de consumo que tendem a tratar os eventos como atrativos comerciais, tanto pelas populações residentes, quanto pelos turistas, cabendo assim aos gestores públicos e privados encontrarem os meios de perpetuar e preservar as manifestações culturais, respeitando as mudanças naturais que ocorrem através dos tempos, sem perder a imagem e caracteres exclusivos. "Ocorre que para a valorização de tais manifestações culturais dependem dos interesses dos meios oficiais de apoio e de setores com ampla visão cultural para tal proposta" (RIBEIRO, 2004).

Entretanto, na maioria das vezes as políticas culturais são influenciadas pelo gosto das elites (RIBEIRO, 2004), esquecendo-se das camadas populares. Esse método, apesar de histórico no Brasil, deve ser evitado tentando incluir no processo de construção da identidade cultural as minorias e as camadas marginalizadas da população.

Apesar de alguns fatores negativos o turismo cultural e as festas populares não são incompatíveis, desde que existam mecanismos de proteção e distanciamento entre ambas as partes, é possível e viável haver sinergias positivas, mas, para isso, devem existir políticas públicas para preservar, promover, respeitar e propiciar exercícios de cidadania aos atores envolvidos no processo. 


\section{Brasil o país do Carnaval?}

O Brasil é considerado por muitos como o "País do Carnaval", mas de acordo com pesquisas citadas a maioria da população é avessa aos festeiros carnavalescos. O Instituto Sensus de pesquisa realizou nos dias 04 e 06 de fevereiro de 2004 uma pesquisa nacional encomendada pela CNT sobre diversos assuntos relacionados a problemas de ordem nacional. Uma das questões tratadas nesse trabalho diz respeito ao carnaval, quando perguntado aos entrevistados se eles gostam ou não desse tipo de festejo e o que eles planejavam fazer no respectivo feriado.

A metodologia adotada foi a seguinte: "2000 Entrevistas, ponderadas para 5 Regiões e 24 Estados, com o sorteio aleatório de 195 Municípios por representatividade de grupos populacionais. Probabilística sistemática até o Setor Censitário para Urbano e Rural, com cotas para Sexo, Idade e Escolaridade no Setor Censitário, e coleta de Renda no Setor Censitário" (SENSUS, 2004). Para validade da pesquisa foi feita uma rechecagem de $20 \%$ do universo amostral. A margem de confiança é de $95 \%$, com uma margem de erro de $3 \%$, considerada absolutamente normal e confiável para uma pesquisa destas proporções.

A primeira questão, que causou a maior surpresa, foi o questionamento se o brasileiro gosta ou não do carnaval. Para uma maioria significativa $57,4 \%$ dos entrevistados afirmaram não gostarem dos festejos momescos. Conforme a Tabela 1 podese observar que em todas as regiões do país, os resultados foram semelhantes. A região com maior repulsa ao carnaval é a região Sul, onde $67,6 \%$ afirmaram não apreciá-lo. A região na qual o carnaval é admirado por um percentual maior dos entrevistados é a região Centro-Oeste com $46,7 \%$. A região Sudeste, onde se concentra o maior contingente populacional e, ainda, as maiores economias e os grandes emissores turísticos do Brasil, 55\% afirmaram não gostar do carnaval.

Tabela 1: Opinião dos entrevistados divididos por região do país sobre gostar ou não do carnaval.

Table 1: Opinion of respondents divided by region of the country about to like or not the Carnival.

\begin{tabular}{|c|c|c|c|c|c|c|c|c|c|c|c|c|}
\hline \multirow[b]{3}{*}{ Sim } & \multicolumn{2}{|c|}{ Nordeste } & \multicolumn{2}{|c|}{ Sul } & \multicolumn{2}{|c|}{ Sudeste } & \multicolumn{2}{|c|}{ Norte } & \multicolumn{2}{|c|}{$\begin{array}{c}\text { Centro- } \\
\text { Oeste }\end{array}$} & \multicolumn{2}{|c|}{ Total } \\
\hline & Abs & $\%$ & Abs. & $\%$ & Abs. & $\%$ & Abs. & $\%$ & Abs. & $\%$ & Abs & $\%$ \\
\hline & 234 & 41,6 & 93 & 31,4 & 378 & 44,4 & 55 & 36,2 & 64 & 6,7 & 824 & 41,2 \\
\hline Não & 311 & 55,2 & 200 & 67,6 & 469 & 55,0 & 97,0 & 63,8 & 71 & 51,8 & 1148 & 57,4 \\
\hline$N S / N R$ & 18 & 3,2 & 3 & 1,0 & 5 & 0,6 & 0 & 0 & 2 & 1,5 & 28 & 1,4 \\
\hline Total & 563 & 28,15 & 296 & 14,8 & 852 & 42,6 & 152 & 7,6 & 137 & 6,85 & 2000 & 100,0 \\
\hline
\end{tabular}

Fonte: CNT / Sensus (2004). Source: CNT / Sensus (2004).

Já na segunda pergunta, referida na Tabela 2, e seguindo a tendência da pes- 
quisa, 49\% afirmaram que pretendiam descansar em casa e 19,4\% somente acompanhariam os desfiles pela televisão. Já $21,3 \%$ pretendiam "pular" carnaval, mas a maioria deles $15 \%$, faria isso na própria cidade de residência. E 6,4\% pretendiam viajar para descansar, incluindo passeios a sítios, retiros e casa de familiares.

Tabela 2: O que os entrevistados pretendiam fazer durante o carnaval.

Table 2: What The respondents intended to do during the carnival.

\begin{tabular}{|c|c|c|}
\hline & Abs. & $\%$ \\
\cline { 2 - 3 } Descansar em casa & 980 & 49,0 \\
Acompanhar pela TV & 388 & 19,4 \\
Brincar nas ruas e clu- & & \\
bes & 299 & 15,0 \\
Viajar para descasar & 127 & 6,4 \\
Viajar para brincar NS/ & 126 & 6,3 \\
NR & 80 & 4,0 \\
Total & 2000 & 100,0 \\
\hline
\end{tabular}

Fonte: CNT / Sensus (2004). Source: CNT / Sensus (2004).

Por meio dos dados apontados pela pesquisa, pode-se concluir que no chamado "País do Carnaval", os festejos momescos já não possuem tanto apelo popular, e a maioria da população afirma não gostar das festas e procura se refugiar delas. Mesmo entre os que gostam, uma relevante parcela o acompanham pela televisão em seus lares.

\section{Organização do carnaval de Belo Horizonte}

A Belotur busca desde 2004 o resgate ou a criação da identidade cultural do carnaval de Belo Horizonte. Para isso, a sua organização, nos três anos anteriores (2003, 2002 e 2001) se basearam em cinco pilares básicos:

- Corso Carnavalesco;

- Bandas Carnavalescas;

- Baile Popular;

- Blocos Caricatos;

- Escolas de Samba.

Outro fator que ajudou na organização foi à criação da Liga das Agremiações Carnavalescas de Minas Gerais (LIAC) em agosto de 2003. Nasceu na junção da antiga União das Escolas de Samba e Blocos Caricatos de Minas Gerais e a Liga Independente de Blocos Caricatos e Carnavalescos de Belo Horizonte. 


\section{Local dos Desfiles}

Após vários anos ocorrendo em um local afastado do centro da cidade na Avenida Risoleta Neves (antiga Via 240) no Bairro novo Aarão Reis, região Nordeste de Belo Horizonte o que afastava grande parte da população, após o ano de 2011 os desfiles voltaram a ocorrer no centro da cidade, na Praça da Estação e na Avenida dos Andradas, no centro da cidade que é de fácil acesso vindo de todas as regiões da capital.

Mesmo assim, a antiga tendência que ocorria no Bairro Aarão Reis continuou a ser notada de que grande parte do público dos desfiles é composta principalmente por pessoas pertencentes às camadas menos favorecidas economicamente da população que são impossibilitados de viajar para carnavais fora da cidade.

Os desfiles em Belo Horizonte ocorrem no sábado de carnaval com os blocos caricatos e no domingo e segunda-feira de carnaval com as escolas de samba. $O$ ingresso para as arquibancadas tem sido adquirido mediante a doação de dois quilos de alimentos não perecíveis, destinados às instituições beneficentes na cidade.

\section{Eventos Alternativos ao Carnaval}

Conforme foi dito anteriormente, muitos defendem que Belo Horizonte se "assuma" como cidade do não carnaval. Para essas pessoas é praticamente impossível a cidade reverter o movimento de fuga de foliões durante os dias da folia e, por isso, a cidade deve investir em eventos que possam atrair turistas que não gostam de carnaval, e que de acordo com a pesquisa CNT/Sensus, representa aproximadamente $57 \%$ da população brasileira.

Essa teoria pode ser reforçada, de acordo uma informação colhida junto ao diretor de marketing do Ouro Minas Palace Hotel, Alexandre Drummond, o qual afirma que durante o período houve uma taxa de ocupação da ordem de $60 \%$ em confronto com uma média de $40 \%$ no restante dos finais de semana. Afirma ainda, que chegaram ao hotel 13 ônibus executivos vindos de várias partes do Brasil, sendo essas pessoas tinham como motivação principal, geralmente, a fuga do carnaval em suas cidades. Algumas iniciativas já foram tomadas sentido, contando ou não com ajuda oficial, mas a maioria não teve sucesso e todas até o momento foram pontuais.

\section{Carnaval Revolução}

O Carnaval Revolução foi um evento que aconteceu entre 2002 e 2008 em Belo Horizonte, organizado pela célula mineira do movimento Anticultura Internacional (ACl). É baseado em palestras e discussões sobre a transformação cultural por meio da organização da sociedade civil organizada e da luta contra o capitalismo interna- 
cional. Além de palestras e mesas redondas, também ocorrem apresentações de teatro, cinema, grupos musicais e campeonatos de futebol, tudo isso seguindo a cartilha do "faça você mesmo". A organização do evento é horizontal e não hierárquica, podendo qualquer um ser voluntário.

Não há regras nem normas, tomando como exemplo o campeonato de futebol que é organizado pelos participantes que não seguem as regras formais do esporte, sendo que antes de cada partida as equipes participantes decidem como será o jogo. Juntamente com o Carnaval Revolução, ocorre O Encontro Nacional de Rádios Livres, O Antifestival Nonsense de Bandas, O Ponto de Compartilhamento Livre e $\mathrm{O} 1^{\circ}$ Campeonato Universal de Futebol Autônomo.

Mesmo com todo esse caráter anárquico, o Carnaval Revolução chegou a conseguir certa divulgação, tendo sido feitas reportagens a respeito em grandes jornais de Minas Gerais, São Paulo, Israel, França, em diversos sítios de Internet e até mesmo no canal de televisão MTV. Porém em 2009, devido a uma participação cada vez menor da população, o evento deixou de existir.

\section{Carnavaliza BH}

Em 2010 um grupo de jovens, composto principalmente de universitários, criou um movimento denominado Carnavaliza $\mathrm{BH}$, tendo por objetivo resgatar um carnaval mais tradicional, sem influências Baianas e Cariocas, voltado principalmente para a organização de blocos e marchinhas, mas sem a participação dos órgãos oficiais como a Belotur. No primeiro ano ocorreram alguns blocos nos bairros de Santa Efigênia e no boêmio Bairro de Santa Tereza. Nos anos seguintes o evento cresceu e no ano de 2012, por meio da divulgação, principalmente através das redes sociais na internet, contou com a participação de centenas de pessoas que queriam aproveitar o carnaval de forma irreverente e independente do poder público.

No mesmo ano ocorreu uma rara popularização de algumas marchinhas criadas pelo movimento, sendo que uma delas faz referência a um conhecido político da cidade e um suposto mau uso do dinheiro público. A marchinha teve milhares de visualizações no site de compartilhamento de vídeo Youtube e gerou bastante polêmica. No ano seguinte, o movimento tomou proporções bem maiores que o previsto pelos organizadores e pela prefeitura (OLIVEIRA; KIEFER, 2013), quando alguns blocos nos quais eram estimados a participação de 500 a 1000 pessoas de acordo com a participação em anos anteriores teve um público presente de aproximadamente 12 mil pessoas. Porém este movimento ainda é muito recente e, portanto, não se pode fazer uma análise mais detalhada do mesmo. Entretanto é notada uma tendência de uma parcela da população que está se interessando cada vez mais pelo movimento Carnavaliza $\mathrm{BH}$. 


\section{Conclusão}

O carnaval de Belo Horizonte não conseguiu até hoje envolver e sensibilizar a maior parte da população da cidade. Mesmo com o público nos desfiles sendo cada vez maior nos últimos anos, nota-se que a maioria permanece alheia às festas.

O carnaval na cidade não se baseia só nas escolas de samba, sendo que a própria Belotur usa cinco pilares básicos para tentar criar uma identidade para o carnaval. Os gestores públicos sabem que apenas repetindo as mesmas manifestações culturais comuns às outras cidades será praticamente impossível Belo Horizonte competir com destinos turísticos mais consolidados para essa época do ano.

Pode-se ver que pela primeira vez em Belo Horizonte o carnaval tem sido planejado com antecedência. Foi criada a LIAC, como citado anteriormente, com o intuito de congregar as agremiações e, juntamente com a Belotur, tem-se realizados seminários para repensar e criar estratégias para propiciar o crescimento da folia na cidade.

Paralelamente eventos como o Carnavaliza $\mathrm{BH}$ apresenta nos últimos anos um crescimento significativo e pode com o tempo se tornar uma manifestação espontânea e popular das festas na capital mineira, o que demonstra o interesse crescente de uma parcela da população, principalmente formada por jovens de classe média, em fomentar uma festa com identidade própria sem copiar modelos estabelecidos em outras cidades ou estados.

Quanto aos custos do carnaval, muito criticado pelos que defendem o seu fim em Belo Horizonte, pode-se dizer que são pequenos, levando-se em conta a arrecadação municipal. Conforme o balanço publicado pela Prefeitura, a cidade arrecadou no ano de 2005 aproximadamente 3,5 bilhões de reais e o gasto declarado no carnaval foi de 630 mil reais, ou seja, $0,02 \%$ da arrecadação municipal. Mesmo levando-se em conta 0 gasto dividido por habitantes, tem-se aproximadamente $R \$ 0,27$. Esses indicadores mostram que em termos de custos o carnaval de Belo Horizonte é extremamente viável e barato.

Contando que a efetiva participação dos moradores da cidade é muito baixa pode-se questionar esses gastos. De acordo com estatísticas correntes, quase 500 mil moradores deixam a cidade no carnaval ou $11 \%$ da população local. Segundo pesquisas recentes, $57 \%$ dos entrevistados não apreciam as festas carnavalescas. É importante ressaltar que uma grande parcela da população que o aprecia possui condições financeiras de viajar. Essas pessoas que não apreciam a festa não devem ser ignoradas pelo poder público, e por isso a Belotur insiste na realização do carnaval.

Quanto a eventos alternativos, esta parece realmente ser a única opção em médio prazo de atratividade turística em Belo Horizonte no período carnavalesco. Contudo é notória a importância do apoio oficial para a realização do carnaval principalmente atendendo a população mais pobre e consequentemente com menos opções de lazer. O investimento em eventos alternativos para tentar atrair turistas que fogem do carnaval pode ser bastante interessante e não concorre de forma nenhuma com as festas carnavalescas tendo em vista o tamanho da cidade e a realização ainda tímida de blocos e desfiles que ocorrem em regiões pontuais da cidade. 


\section{Referências bibliográficas}

ARAÚJO, M. Carnaval: Uma abordagem psico-sociológica. Tese: Belo Horizonte, 1991.

BARRETO, A. O Primeiro Carnaval de Belo Horizonte: Minas Gerais. Belo Horizonte,12 mar. 1929 , p. 7.

BATISTA, C.M. Memória e identidade: Aspectos relevantes para o desenvolvimento do turismo cultural. Caderno Virtual do Turismo: Rio de Janeiro, 2005. Disponível em: http://www.ivt-ri.net/caderno/anteriores/17/cvt17 27 33/cvt17 27 33.htm. Acesso em: 22 fev. 2006.

BENI, M.C.. Análise Estrutural do Turismo. Senac: São Paulo, 2002.

COELHO, A. Festa e Turismo no Brasil; o Carnaval do Rio de Janeiro. Fundação Getúlio Vargas: São Paulo, 2003. Disponível em: http://www.turismo.gov.br/site/ arquivos/dados fatos/observatorio/FestaeTurismonoBrasil.pdf. Acesso em: 29 mar. 2006.

COSTA, C. R. F; ANDRADE, R. G. Carnaval, samba e comunicação no morro da Mangueira. Anais do XXVI Congresso Brasileiro de Ciência da Comunicação: Belo Horizonte,2003. Disponível em: http://www.intercom.org.br/papers/congresso2003/ pdf/2003 NP17 costa.pdf. Acesso em: 13 abr. 2006.

GIL, A.C. Como elaborar projetos de pesquisa. 3. Ed. São Paulo: Atlas, 1991.

INSTITUTO SENSUS. Pesquisa de Opinião Pública nacional - Rodada 67. Brasília, 6 fev. 2004.

MELÉNDES, A.. Eventos urbanos tradicionales y practicas folkloricas para el turismo cutural patrimonial. The Touristic Historic City Conference: Bruges, Bélgica 2002. Disponível em: http://150.185.222.180/mimeoteca/papers/Eventos\%20urbanos\% 20 \% 20 practicas $\% 20$ folklori cas\%20para\%20el\%20turismo\%20cultural.pdf. Acesso em: 02 mai. 2006.

RIBEIRO, M. Festas Populares e turismo cultural - inserir valor ou esquecer? O caso dos Moçambiques de Osório, Rio Grande do Sul. Passos Revista do Turismo e Patrimônio Cultural. 2004. Disponível em: http://www.pasosonline.org/ Publicados/2104/PS040104.pdf., Acesso em: 10 mai. 2006.

OLIVEIRA, J.; KIEFER, S. Milhares de foliões provam que BH tem vocação para carnaval, mas falta planejamento. Jornal Estado de Minas, 14 de fevereiro de 2013. Disponível em: http://www.em.com.br/app/noticia/gerais/2013/02/14/ interna_gerais,350303/carnaval-renascido-na-capital-mineira-deixa-licoes.shtml. Acesso em: 14 fev. 2013.

RIBEIRO, M. Na Terra do não Carnaval. Jornal Diário do Comércio. Belo Horizonte, 16 fev. 1996. Comunicação e Marketing. 
VELOSO, J. Carnaval não é pra ver, Carnaval é Prapular. Belo Horizonte, 1 mar. 1995. Assessoria de Comunicação da Belotur.

YIN, R.K. Estudo de caso: planejamento e métodos. Bookman: Porto Alegre, 2005.

Solano de Souza Braga: Universidade Federal de Minas Gerais, Belo Horizonte, MG, Brasil.

Email: solanobraga@yahoo.com.br

Link para o currículo Lattes: http://lattes.cnpq.br/3774316982731542

Leandro Martins Vieira: Universidade Federal de Minas Gerais, Belo Horizonte, MG, Brasil.

Email: leandrovieira@globo.com

Link para o currículo Lattes: http://lattes.cnpq.br/0878691565022717

Data de submissão: 30 de junho de 2012

Data de recebimento de correções: 16 de julho de 2013

Data do aceite: 20 de setembro de 2013

Avaliado anonimamente 